\title{
Is a patient-specific drill template via a cortical bone trajectory safe in cervical anterior transpedicular insertion?
}

Peng Peng ${ }^{1+}$, Yafei $\mathrm{Xu}^{2+}$, Xintao Zhang ${ }^{3}$, Meisong Zhu ${ }^{4}$, Bingran $\mathrm{Du}^{1}$, Wenrui $\mathrm{Li}^{1}$, Wenhua Huang ${ }^{1}$, Jun Song ${ }^{5^{*}}$ and Jianyi $\mathrm{Li}^{1 *}$

\begin{abstract}
Background: This study aimed to develop patient-specific drill templates by computer numerical control or threedimensional printing via two cortical bone trajectories (CBTs) and to evaluate their efficacies and accuracies in cervical anterior transpedicular insertion.

Methods: Preoperative $C T$ images of 20 cadaveric cervical vertebrae (C3-C7) were obtained. After image processing, patient-specific drill templates were randomly assigned to be constructed via two CBTs (CBT0 and CBT0.7) and manufactured by two methods (computer numerical control and three-dimensional printing). Guided by patientspecific drill templates, 3.5-mm-diameter screws were inserted into the pedicles. Postoperative CT scans were performed to evaluate the screw deviation in the entry point and midpoint of the pedicle. The screw positions were also graded.

Results: Computer numerical control patient-specific drill templates had a significantly shorter manufacturing time compared to three-dimensional-printed patient-specific drill templates $(p<0.01)$. Absolute deviations at the entry point and midpoint of the pedicle had no significant differences on the transverse and sagittal planes $(p>0.05)$. There were no significant differences in screw positions $(p=0.3)$. However, three screw positions were in grade 3 in CBT0, while the others were in grade 1.

Conclusions: CBT0.7 appears to be a safe and feasible trajectory for cervical anterior transpedicular insertion. Bio-safe computer numerical control patient-specific drill templates can facilitate cervical anterior transpedicular insertion with good feasibility and accuracy.
\end{abstract}

Keywords: Cortical bone trajectory, Patient-specific drill template, Computer numerical control, 3D printing, Computed tomography, Cervical anterior transpedicular insertion

\section{Background}

Anterior cervical decompression and fusion (ACDF) is widespread to treat the subaxial cervical spine diseases $[1,2]$. However, the biomechanical stability is unsatisfied in the cases of single-level three-column injuries or multi-level anterior compression treated with anterior

\footnotetext{
*Correspondence: 124818673@qq.com; lijianyi@outlook.com

†Equal contributors

${ }^{5}$ General Education Department, Southern Medical University, 1063 Shatai Nan Road, Baiyun District, Guangzhou, Guangdong, China

'Department of Anatomy, Guangdong Provincial Key Laboratory of Medical Biomechanics, School of Basic Medical Sciences, Southern Medical University, 1063 Shatai Nan Road, Baiyun District, Guangzhou, Guangdong, China Full list of author information is available at the end of the article
}

vertebral body screws $[3,4]$. As an alternative, the anterior transpedicular screw (ATPS) technique was introduced by Aramomi et al. [5], and it has gradually been more widely applied to cervical stabilization [6-10] since it combines the advantages of an anterior approach with the superior biomechanical characteristics of cervical pedicle fixation [8]. Generally, pedicle fixation is considered risky because it is proximal to the vital structures such as the vertebral arteries, the spinal cord, and the nerve roots $[11,12]$. Therefore, accurate anterior transpedicular insertion (ATPI) is a key to successful clinical application of ATPS.

(c) The Author(s). 2018 Open Access This article is distributed under the terms of the Creative Commons Attribution 4.0 International License (http://creativecommons.org/licenses/by/4.0/), which permits unrestricted use, distribution, and 
Much research has been conducted to achieve accurate ATPI in the cervical spine with fewer risks. Koller et al. [9] reported successful ATPI using the fluoroscopic-guided freehand technique in cadaver research. However, the incidence of a critical pedicle breach in the axial plane was $21.7 \%$. Computer-assisted navigation (CAN) systems were used in ATPI [13]. Patton et al. found that catastrophic screw placement occurred in $33.3 \%$ of cases performed by the fluoroscopic-guided freehand technique; that by CAN was significantly lower, but it was still $16.7 \%$. Patientspecific drill templates (PDTs) produced by threedimensional printing (3DP) were then introduced to assist with cervical transpedicular insertion with good effectiveness and accuracy $[14,15]$. However, the materials used in 3DP are mainly photosensitive resin, which is not biocompatible and cannot be sterilized by high temperatures. Fu et al. [16] tried to develop a biocompatible PDT for ATPI using a bone cement mold according to a 3DP model of the cervical vertebrae with preset screw trajectories. However, their pedicle cortex penetration rate in critical positions was as high as $8.3 \%$, which indicated that it was not an ideal solution for ATPI. Kong et al. [17] developed a bio-safe metal PDT using computer numerical control (CNC) and verified its high accuracy for posterior thoracic pedicle insertions. However, there have been no studies related to PDT by $\mathrm{CNC}$ in cervical applications.

Regarding the trajectory, the current PDTs usually use the center line $(\mathrm{CL})$ of the pedicle as their ideal trajectory, where the screw is mainly engaged with cancellous bone in the pedicle and vertebral body $[6,8,18,19]$. In this situation, it was reported that screw loosening might occur, leading to a loss of correction and nonunion, particularly in patients with poor bone quality [20, 21]. Therefore, Santoni et al. [22] advocated the cortical bone trajectory (CBT), which allowed the screw's thread to contact the cortical bone. It was deemed an acceptable alternative to the CL trajectory for lumbar pedicle screw insertion. Biomechanical studies further demonstrated that the CBT technique achieves a screw purchase and strength greater than the traditional CL trajectory [22-24]. However, no study has been conducted using CBT in the cervical vertebrae.

Therefore, the aims of the study were to develop PDTs with two types of manufacturing methods ( $\mathrm{CNC}$ and 3DP) and two types of CBTs, respectively, and to evaluate their efficacies and accuracies in facilitating ATPI.

\section{Methods}

\section{Specimen collection}

Twenty formalin-preserved cervical vertebrae (range C3-C7) from four human cadavers (three males and one female, ages 45-56) were imaged using a Brilliance CT 64channel scanner (Philips, Eindhoven, The Netherlands). The in-plane pixel size was $0.5 \mathrm{~mm}$, and the slice thickness was $0.5 \mathrm{~mm}$. All cervical vertebrae involved in this study after the CT scan images showed no significant bone defects which were detected by the same radiologist.

\section{Preoperative design of CBT}

Three-dimensional reconstructions were performed using Mimics 14.11 (Materialise Corp., Leuven, Belgium). There were two CBTs in our study. One CBT allowed the screw $(3.5 \mathrm{~mm})$ thread to be close to the medial wall of the pedicle without cortical perforation (CBT0) (Fig. 1a). Since the medial cortical thickness of the cervical pedicle is about $1.4 \mathrm{~mm}$ according to the literature $[25,26]$, in order to allow the screw thread to contact half of the medial cortical wall of the pedicle, a trajectory was designed that allowed the screw thread to be $0.7 \mathrm{~mm}$ lateral from the medial wall of the cervical pedicle (CBT0.7) (Fig. 1b).

\section{Design and manufacturing of PDTs}

Following the preset ATPI trajectories, PDTs were specifically designed for $3 \mathrm{DP}$ or $\mathrm{CNC}$ techniques, respectively, with the characteristics of an inverse surface of the

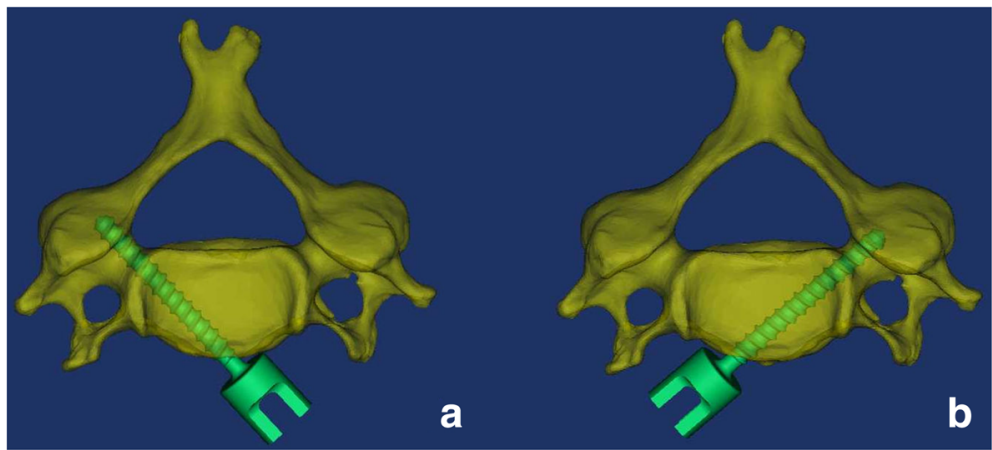

Fig. 1 Two types of preoperative CBT designs. a CBTO allows the screw thread to be close to the medial wall of cervical pedicle. b CBT0.7 allowed the screw thread to be $0.7 \mathrm{~mm}$ lateral from the medial wall of the cervical pedicle 
anterior vertebral body and a preset guiding tract (Fig. 2a, b) [17]. The 3DP-produced PDTs were manufactured by a stereolithography RP printer RS6000 (Shanghai Union 3D Technology Corp., Shanghai, China) with photosensitive resin (Fig. 2c), and the CNC-manufactured PDTs were machined by a VM650 3 Axis CNC (Bochi Machine Tool Group Corp., Shanxi, China) with stainless steel (Fig. 2d). The manufacturing time and cost of each PDT were both recorded.

\section{Surgery}

After the anterior soft tissue was removed from the vertebrae, a total of 40 pedicle sides were randomly assigned into four groups with two trajectories (CBT0 and CBT0.7) and two manufacturing methods (3DP and $\mathrm{CNC}$ ) by random numbering chart. The four groups were as follows: group CBT0-3DP, group CBT0-CNC, group CBT0.7-3DP, and group CBT0.7-CNC. Each PDT was compressed slightly to the anterior surface of the cervical vertebrae. A 2-mm-diameter K-wire was subsequently drilled into the cervical pedicle with the assistance of the PDT (Fig. 3). Finally, a $3.5 \mathrm{~mm}$-diameter screw was inserted.

\section{Assessment of insertion accuracy}

Postoperative CT scans were performed for all cadaveric cervical specimens, and the positions of the screws were extracted. The deviations between the preoperatively designed and postoperatively measured screw trajectories were calculated at the entry point and middle point of the pedicle on the transverse and sagittal planes, respectively. The transverse plane's deviations toward the lateral side were recorded as positive values and the deviations toward the medial side as negative values. The sagittal plane's deviations toward the superior and inferior sides were recorded as positive and negative values, respectively $[16,17]$.

A grade was then used to evaluate breaches of the pedicle wall in the sagittal and transverse planes as follows:

Grade 1: Screw positioned at the center of the pedicle Grade 2: Less than one third of the screw cross-section ( $\leq 1.2 \mathrm{~mm}$ with a $3.5-\mathrm{mm}$-diameter screw) penetrating the cortex

Grade 3: Between one third and one half of the screw cross-section penetrating the cortex (or deviation $<2 \mathrm{~mm}$ )

Grade 4: More than one half of the screw cross-section penetrating the cortex (or deviation $\geq 2 \mathrm{~mm}$ )

Grade 5: Deviation equal to or greater than the screw diameter [9-11]

Non-critical pedicle breaches corresponded to grades 1 and 2. Critical pedicle breaches, with the potential risk of neurovascular injury, corresponded to grades 3-5 [10].

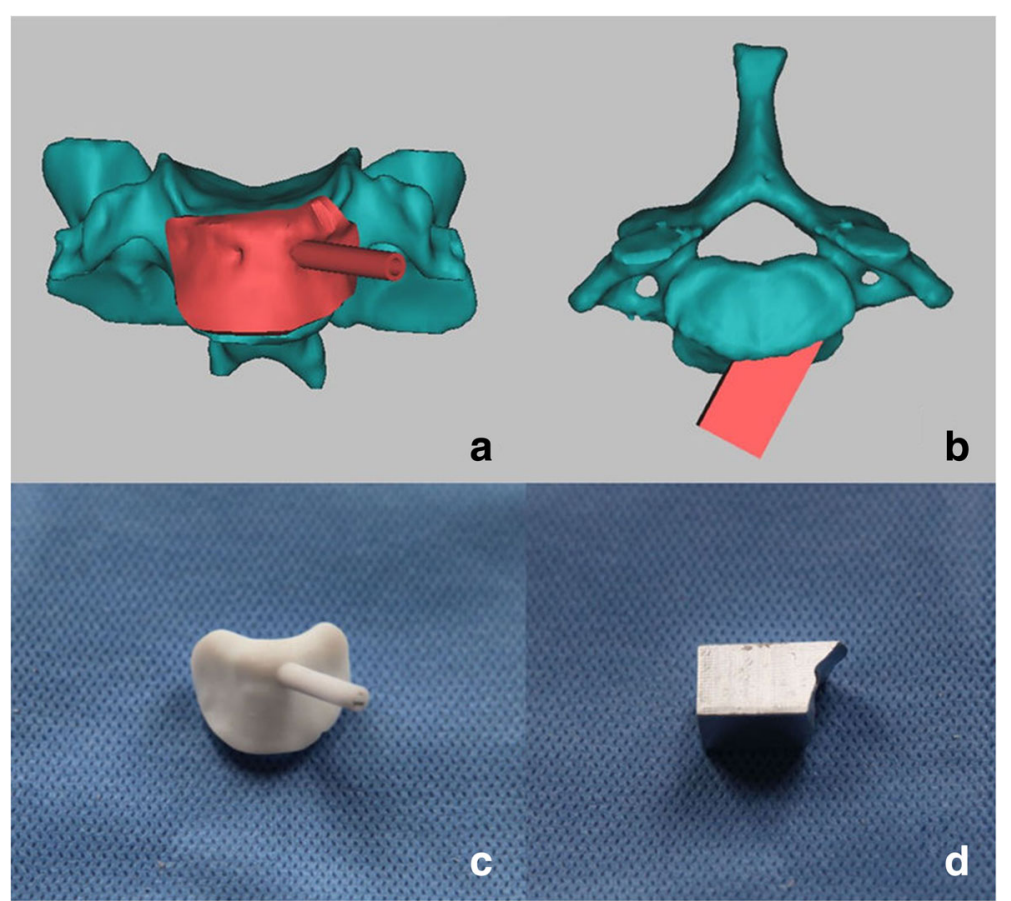

Fig. 2 Design and manufacturing of two types of PDTs. The 3DP-produced PDTs were designed and produced with a photosensitive resin (a, c). CNC-manufactured PDTs were designed and produced with stainless steel $(\mathbf{b}, \mathbf{d})$ 


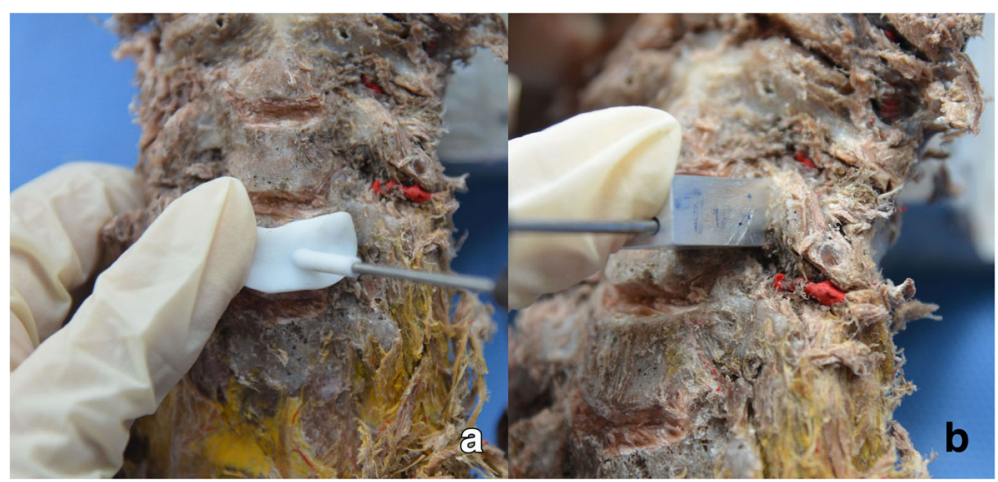

Fig. 3 Two-millimeter-diameter K-wires were inserted into cadaveric cervical vertebrae with PDTs. a A K-wire was drilled into the cervical pedicle guided by the 3DP-produced PDT. b A K-wire was inserted, guided by the CNC-manufactured PDT

\section{Statistical analysis}

Results on manufacturing time, price, and deviations are presented as means \pm standard deviation. Categorical measurements are presented as numbers. Factorial analysis was used to analyze the absolute deviations of screws between the four groups on the transverse and sagittal planes. The chi-square test was performed to compare the grade of ATPS. SPSS 20 (IBM, the United States) was used for all analyses, and the significance was defined as $p<0.05$.

\section{Results}

All PDTs were produced successfully by CNC or 3DP. Their manufacture time was $51.65 \pm 3.56 \mathrm{~min}$ and 109 . $75 \pm 3.88 \mathrm{~min}$, respectively, with significant differences $(t=45.35, p<0.001)$. The cost was $16.44 \pm 0.64$ dollars and $16.72 \pm 1.07$ dollars, respectively, with no significant differences $(t=-1.796, p=0.082)$. During the operation, all screws were inserted into the cervical pedicle easily with the assistance of PDTs.

The absolute deviations at the entry point and middle point of the pedicle on the transverse and sagittal planes are presented in Table 1 . There were no significant differences between the two types of CBTs on the transverse and sagittal planes at the entry point $(F=0.299, p$ $=0.588$, and $F=0.079, p=0.780$, respectively) or at the

Table 1 The absolute deviations at the entry point and middle point of the pedicle on the transverse and sagittal planes (mean \pm SD, $\mathrm{mm}$ )

\begin{tabular}{|c|c|c|c|c|}
\hline \multirow[t]{2}{*}{ Group } & \multicolumn{2}{|l|}{ Entry point } & \multicolumn{2}{|l|}{ Midpoint } \\
\hline & $\begin{array}{l}\text { Transverse } \\
\text { plane }\end{array}$ & $\begin{array}{l}\text { Sagittal } \\
\text { plane }\end{array}$ & $\begin{array}{l}\text { Transverse } \\
\text { plane }\end{array}$ & $\begin{array}{l}\text { Sagittal } \\
\text { plane }\end{array}$ \\
\hline Group CBT0-3DP & $0.57 \pm 0.28$ & $0.20 \pm 0.11$ & $0.82 \pm 0.47$ & $0.48 \pm 0.45$ \\
\hline Group CBTO-CNC & $0.44 \pm 0.22$ & $0.15 \pm 0.10$ & $0.65 \pm 0.36$ & $0.40 \pm 0.47$ \\
\hline Group CBT0.7-3DP & $0.52 \pm 0.39$ & $0.13 \pm 0.12$ & $0.64 \pm 0.28$ & $0.49 \pm 0.46$ \\
\hline Group CBT0.7-CNC & $0.54 \pm 0.33$ & $0.20 \pm 0.13$ & $0.54 \pm 0.34$ & $0.61 \pm 0.35$ \\
\hline
\end{tabular}

midpoint of pedicle $(F=1.267, p=0.268$, and $F=0.016$, $p=0.901$, respectively). Similarly, there were also no significant differences between the two manufacturing methods on the transverse and sagittal planes at the entry point $(F=0.069, p=0.759$, and $F=0.025, p=0.875$, respectively) or at the midpoint of pedicle $(F=1.552, p$ $=0.221$, and $F=0.601, p=0.443$, respectively).

The grades of screw insertion positions are shown in Table 2. There were nine (90\%) in grade 1 and one (10\%) in grade 3 in the CBT0-3DP group and eight $(80 \%)$ in grade 1 and two (20\%) in grade 3 in the CBT0$\mathrm{CNC}$ group, whereas all screws were in grade 1 in the CBT0.7-3DP group and the CBT0.7-CNC group (Fig. 4). There were no significant differences between the four groups $\left(X^{2}=7.11, p=0.300\right)$.

\section{Discussion}

In this study, we developed the PDTs with two types of CBTs (CBT0 and CBT0.7) and two manufacturing methods (3DP and $\mathrm{CNC}$ ). The efficacies and accuracies of these PDTs in facilitating cervical ATPI were further evaluated. These results revealed that the CBT0.7 might be a safer trajectory for cervical ATPI. Meanwhile, with its time-saving and bio-safe merits, $\mathrm{CNC}$ might be an alternative manufacturing method for PDTs in cervical ATPI.

In our study, two manufacturing techniques, 3DP and $\mathrm{CNC}$, were used. Actually, the major difference between 3DP and CNC was the additive or subtractive manufacturing techniques they used. To our knowledge, most

Table 2 Safety of screw insertion classifications

\begin{tabular}{llllll}
\hline Group & Grade 1 & Grade 2 & Grade 3 & Grade 4 & Grade 5 \\
\hline Group CBT0-3DP & $9(90 \%)$ & 0 & $1(10 \%)$ & 0 & 0 \\
Group CBT0-CNC & $8(80 \%)$ & 0 & $2(20 \%)$ & 0 & 0 \\
Group CBT0.7-3DP & $10(100 \%)$ & 0 & 0 & 0 & 0 \\
Group CBT0.7-CNC & $10(100 \%)$ & 0 & 0 & 0 & 0 \\
Total & 37 & 0 & 3 & 0 & 0 \\
\hline
\end{tabular}




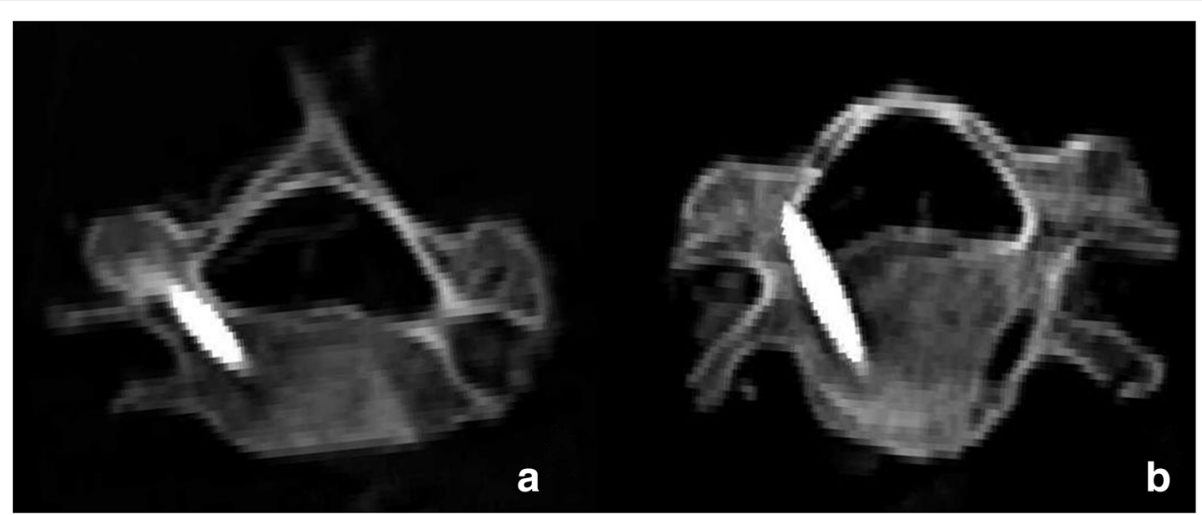

Fig. 4 Grades of screw insertion position. a Grade 1 indicates a screw positioned at the center of the pedicle without cortical bone breach. $\mathbf{b}$ Grade 3 indicates a screw that penetrated the cortex between one third and one half of the screw diameter

research related to PDTs used 3DP because of its merits in complex structure formation [15, 27-29]. This method could be more accurate than the free-hand insertion techniques. However, they mainly use nonbiocompatible photosensitive resin. Moreover, they cannot be sterilized at high temperatures. Drilling debris that contacts the wound would bring certain risks. In an attempt to overcome these limitations, Kong et al. [17] used CNC to produce biocompatible metal PDTs and further confirmed their efficacy and accuracy in posterior thoracic pedicle insertion. In our study, CNC was also used to design and produce metal PDTs for cervical ATPI. These CNC-manufactured PDTs were not only biocompatible but also highly precise with free-form surface formations. It should be mentioned that a deep concave could not be created by $\mathrm{CNC}$ because of the cutting and routing limitations of the subtractive manufacturing technology. All CNC-manufactured PDT designs should be specially examined and optimized. In our study, since the anterior surface of the cervical vertebrae was relatively flat, there was no deep concave in any of the CNC-manufactured PDTs. The CNCmanufactured PDTs achieved high efficacies and accuracies in facilitating cervical ATPI and were advantageous by saving time in manufacturing compared with 3DPproduced PDTs. However, the total time was about $12 \mathrm{~h}$ from acquiring the CT image to obtaining the PDTs, which was a little longer, but might be acceptable for most of the surgeries. Therefore, CNC-manufactured PDTs can be a viable alternative to 3DP-PDTs and could also provide surgeons with a bio-safe, accurate method for cervical ATPI.

In terms of surgical safety, accurate pedicle screw placement and sufficient strength and rigidity of fixation are two major aspects that should concern spinal surgeons. CBT is a novel concept that may provide better implantation strength with the screw's thread contacting the cortical bone of the pedicle [22-24]. In this circumstance, accurate placement of the pedicle screw with CBT is of vital importance since it has a great probability of pedicle perforation in screw insertion. Therefore, the second objective of this study was to evaluate the accuracy of the two types of CBTs in cervical ATPI.

There were two major considerations about CBT in our study. One was the direction of the CBT. Other than lumbar lateral CBT in the transverse plane [22], CBT in cervical ATPI was designed to be medial because of the lateral structures of the vertebral artery. Previous studies have indicated that lateral perforation was observed more frequently [30,31], and the consequences of a lateral perforation in the cervical spine, such as cerebral infarction, are serious [32]. In contrast, medial CBT might be safer since the dural sac is located at a distance of approximately $2.4-3.1 \mathrm{~mm}$ from the medial pedicle wall [33]. Therefore, we designed the CBT in cervical ATPI to be medial in order to allow the screw thread to approach the medial wall of the pedicle. The second consideration was the setting of the two types of CBTs. One was the CBT0 that allowed the screw thread to be close to the medial wall of the pedicle without cortical perforation. Another was the CBT0.7 that allowed the screw thread to be $0.7 \mathrm{~mm}$ lateral from the medial wall of the cervical pedicle. Since the medial cortical thickness of the cervical pedicle is about $1.4 \mathrm{~mm}[25,26]$, CBT0.7 meant that the screw thread contacted half of the medial cortical wall of the pedicle. Moreover, a distance of $0.7 \mathrm{~mm}$ lateral from the medial wall of the cervical pedicle would allow the pedicle insertion a deviation tolerance. CBT0.7 would be safe for pedicle insertion because PDT's insertion accuracy was shown to be between 0.4 and $0.7 \mathrm{~mm}$ at the midpoint of the thoracic pedicles in our previous research [17]. Therefore, in our study, we designed two types of CBTs, CBT0 and CBT0.7, and further evaluated their efficacies and accuracies. 
Although no significant differences for screw deviations were observed between CBT0 and CBT0.7, three critical breaches (grade 3) occurred with CBT0. The high rate of critical pedicle breach that existed with CBT0 is unacceptable for clinical application, as it may carry a risk of neurovascular injury. Additionally, we found that most screws in grade 1 deviated laterally. This is probably because the medial pedicle wall is thicker. We inferred that when the tip of the K-wire or the screw contacted the medial wall of the cervical pedicle, the thick and tough medial cortical bone would push it outward, which made ATPI with CBT0.7 safe. Therefore, the CBT0.7 was a safer trajectory with less perforation in cervical ATPI.

Our study has several limitations. First, the design of the CBTs was only offset on the transverse plane, and the sagittal plane was not considered. We will address this in future research. Second, the results of the accuracy of the screw insertions with the new trajectories are satisfying, but biomechanical evaluations such as the pullout strength and cyclic fatigue loading were not evaluated in this study, and this needs further research. Third, the PDTs were only performed on cadaveric spines. Clinical studies are needed.

\section{Conclusion}

In summary, CBT0.7 may be a safe and feasible trajectory in cervical ATPI. The bio-safe CNC-PDTs are viable in facilitating cervical ATPI with good feasibility and accuracy.

\section{Abbreviations}

3DP: Three-dimensional printing; ACDF: Anterior cervical decompression and fusion; ATPI: Anterior transpedicular insertion; ATPS: Anterior transpedicular screw; CAN: Computer-assisted navigation; CBT: Cortical bone trajectory; CL: Center line; CNC: Computer numerical control; PDT: Patient-specific drill template

\section{Funding}

This study was funded by the National Natural Science Foundation of China (NSFC) (31771330), National Key Research and Development Program of China (2017YFC0110602), and Guangdong and Guangzhou provincial scientific and technique program (2014A020212200, 2015A040404022, 2015B010125006, 2015B010125005, 201704020129, and 201704020069).

\section{Availability of data and materials}

Supporting data is available.

\section{Authors' contributions}

$P P, Y X$, and $J$ participated in the design of this study. PP, $X Z$, and $M Z$ carried out the study. BD, WL, and $\mathrm{WH}$ collected the data and performed the data analysis. PP, JS, and JL wrote the manuscript. All authors read and approved the final manuscript.

\section{Ethics approval and consent to participate}

This study was approved by the Ethics Committee of Southern Medical University, and the participants' next of kin provided informed consent before commencing the present study.

\section{Competing interests}

The authors declare that they have no competing interests.

\section{Publisher's Note}

Springer Nature remains neutral with regard to jurisdictional claims in published maps and institutional affiliations.

\section{Author details}

'Department of Anatomy, Guangdong Provincial Key Laboratory of Medical Biomechanics, School of Basic Medical Sciences, Southern Medical University, 1063 Shatai Nan Road, Baiyun District, Guangzhou, Guangdong, China. 2Department of Orthopedics, Nanhai Hospital, Southern Medical University, 28 Liguan Road, Nanhai District, Foshan, Guangdong, China. ${ }^{3}$ Department of Radiology, The Third Affiliated Hospital, Southern Medical University, 183 Zhongshandadao Xi, Tianhe District, Guangzhou, Guangdong, China. ${ }^{4}$ Department of Orthopedics, Zhujiang Hospital, Southern Medical University, 253 Gongye Street, Haizhu District, Guangzhou, Guangdong, China. ${ }^{5}$ General Education Department, Southern Medical University, 1063 Shatai Nan Road, Baiyun District, Guangzhou, Guangdong, China.

Received: 6 February 2018 Accepted: 5 April 2018

Published online: 18 April 2018

\section{References}

1. Jiang $L$, Tan $M$, Dong $L$, Yang F, Yi $P$, Tang $X$, et al. Comparison of anterior decompression and fusion with posterior laminoplasty for multilevel cervica compressive myelopathy: a systematic review and meta-analysis. J Spinal Disord Tech. 2015;28(8):282-90

2. Daentzer D, Boker DK. Operative stabilization of traumatic instabilities of the lower cervical spine. Experience with an angle instable anterior plate-screw system in 95 patients. Unfallchirurg. 2004;107(3):175-80.

3. Epstein NE. Reoperation rates for acute graft extrusion and pseudarthrosis after one-level anterior corpectomy and fusion with and without plate instrumentation: etiology and corrective management. Surg Neurol. 2001; 56(2):73-80. discussion 80-1

4. Henriques $\mathrm{T}$, Olerud $\mathrm{C}$, Bergman $\mathrm{A}$, Jonsson $\mathrm{HJ}$. Distractive flexion injuries of the subaxial cervical spine treated with anterior plate alone. J Spinal Disord Tech. 2004:17(1):1-7.

5. Aramomi M, Masaki Y, Koshizuka S, Kadota R, Okawa A, Koda M, et al. Anterior pedicle screw fixation for multilevel cervical corpectomy and spinal fusion. Acta Neurochir. 2008;150(6):575-82.

6. Yukawa Y, Kato F, Ito K, Nakashima H, Machino M. Anterior cervical pedicle screw and plate fixation using fluoroscope-assisted pedicle axis view imaging: a preliminary report of a new cervical reconstruction technique. Eur Spine J. 2009:18(6):911-6.

7. Zhang Z, Mu Z, Zheng W. Anterior pedicle screw and plate fixation for cervical facet dislocation: case series and technical note. Spine J. 2016:16(1):123-9.

8. Koller H, Hempfing A, Acosta F, Fox M, Scheiter A, Tauber M, et al. Cervical anterior transpedicular screw fixation. Part I: study on morphological feasibility, indications, and technical prerequisites. Eur Spine J. 2008;17(4):523-38.

9. Koller H, Acosta F, Tauber M, Fox M, Martin H, Forstner R, et al. Cervical anterior transpedicular screw fixation (ATPS) —Part II. Accuracy of manual insertion and pull-out strength of ATPS. Eur Spine J. 2008;17(4):539-55.

10. Koller H, Hitzl W, Acosta F, Tauber M, Zenner J, Resch H, et al. In vitro study of accuracy of cervical pedicle screw insertion using an electronic conductivity device (ATPS part III). Eur Spine J. 2009;18(9):1300-13.

11. Tomasino A, Parikh K, Koller H, Zink W, Tsiouris AJ, Steinberger J, et al. The vertebral artery and the cervical pedicle: morphometric analysis of a critical neighborhood. J Neurosurg Spine. 2010;13(1):52-60.

12. Kotil K, Akcetin MA, Savas Y. Neurovascular complications of cervical pedicle screw fixation. J Clin Neurosci. 2012;19(4):546-51.

13. Patton AG, Morris RP, Kuo YF, Lindsey RW. Accuracy of fluoroscopy versus computer-assisted navigation for the placement of anterior cervical pedicle screws. Spine (Phila Pa 1976). 2015;40(7):E404-10.

14. Lu S, Xu YQ, Chen GP, Zhang YZ, Lu D, Chen YB, et al. Efficacy and accuracy of a novel rapid prototyping drill template for cervical pedicle screw placement. COMPUT AIDED SURG. 2011;16(5):240-8.

15. Kaneyama S, Sugawara T, Sumi M. Safe and accurate midcervical pedicle screw insertion procedure with the patient-specific screw guide template system. Spine (Phila Pa 1976). 2015:40(6):E341-8.

16. Fu M, Lin L, Kong X, Zhao W, Tang L, Li J, et al. Construction and accuracy assessment of patient-specific biocompatible drill template for cervical anterior transpedicular screw (ATPS) insertion: an in vitro study. PLoS One. 2013;8(1):e53580. 
17. Kong $X$, Tang L, Ye Q, Huang W, Li J. Are computer numerical control (CNC)-manufactured patient-specific metal templates available for posterior thoracic pedicle screw insertion? Feasibility and accuracy evaluation. Eur Spine J. 2017; https://doi.org/10.1007/s00586-017-5215-3.

18. Zhao L, Li G, Liu J, Benedict GM, Ebraheim NA, Ma W, et al. Radiological studies on the best entry point and trajectory of anterior cervical pedicle screw in the lower cervical spine. Eur Spine J. 2014;23(10):2175-81.

19. Li J, Zhao L, Liu W, Ma W, Xu R, Jiang WY, et al. Anterior transpedicular screws in conjunction with plate fixation and fusion for the treatment of subaxial cervical spine diseases. Eur Spine J. 2015;24(8):1681-90.

20. Wittenberg RH, Shea M, Swartz DE, Lee KS, White AR, Hayes WC. Importance of bone mineral density in instrumented spine fusions. Spine (Phila Pa 1976). 1991;16(6):647-52.

21. Halvorson TL, Kelley LA, Thomas KA, Whitecloud TR, Cook SD. Effects of bone mineral density on pedicle screw fixation. Spine (Phila Pa 1976). 1994; 19(21):2415-20.

22. Santoni BG, Hynes RA, McGilvray KC, Rodriguez-Canessa G, Lyons AS, Henson MA, et al. Cortical bone trajectory for lumbar pedicle screws. Spine J. 2009;9(5):366-73.

23. Perez-Orribo L, Kalb S, Reyes PM, Chang SW, Crawford NR. Biomechanics of lumbar cortical screw-rod fixation versus pedicle screw-rod fixation with and without interbody support. Spine (Phila Pa 1976). 2013;38(8):635-41.

24. Matsukawa K, Yato Y, Kato T, Imabayashi H, Asazuma T, Nemoto K. In vivo analysis of insertional torque during pedicle screwing using cortical bone trajectory technique. Spine (Phila Pa 1976). 2014;39(4):E240-5.

25. Karaikovic EE, Daubs MD, Madsen RW, Gaines RJ. Morphologic characteristics of human cervical pedicles. Spine (Phila Pa 1976). 1997;22(5):493-500.

26. Gupta R, Kapoor K, Sharma A, Kochhar S, Garg R. Morphometry of typical cervical vertebrae on dry bones and $C T$ scan and its implications in transpedicular screw placement surgery. Surg Radiol Anat. 2013;35(3):181-9.

27. Takemoto M, Fujibayashi S, Ota E, Otsuki B, Kimura H, Sakamoto T, et al. Additive-manufactured patient-specific titanium templates for thoracic pedicle screw placement: novel design with reduced contact area. Eur Spine J. 2016; 25(6):1698-705.

28. Kawaguchi Y, Nakano M, Yasuda T, Seki S, Hori T, Kimura T. Development of a new technique for pedicle screw and Magerl screw insertion using a 3dimensional image guide. Spine (Phila Pa 1976). 2012;37(23):1983-8,

29. Owen BD, Christensen GE, Reinhardt JM, Ryken TC. Rapid prototype patientspecific drill template for cervical pedicle screw placement. COMPUT AIDED SURG. 2007;12(5):303-8.

30. Yukawa Y, Kato F, Ito K, Horie Y, Hida T, Nakashima H, et al. Placement and complications of cervical pedicle screws in 144 cervical trauma patients using pedicle axis view techniques by fluoroscope. Eur Spine J. 2009;18(9):1293-9.

31. Nakashima H, Yukawa Y, Imagama S, Kanemura T, Kamiya M, Yanase M, et al. Complications of cervical pedicle screw fixation for nontraumatic lesions: a multicenter study of 84 patients. J Neurosurg Spine. 2012;16(3):238-47.

32. Onishi E, Sekimoto Y, Fukumitsu R, Yamagata S, Matsushita M. Cerebral infarction due to an embolism after cervical pedicle screw fixation. Spine (Phila Pa 1976). 2010;35(2):E63-6.

33. Ugur HC, Attar A, Uz A, Tekdemir I, Egemen N, Caglar S, et al. Surgical anatomic evaluation of the cervical pedicle and adjacent neural structures. Neurosurgery. 2000;47(5):1162-8. discussion 1168-9.

\section{Ready to submit your research? Choose BMC and benefit from:}

- fast, convenient online submission

- thorough peer review by experienced researchers in your field

- rapid publication on acceptance

- support for research data, including large and complex data types

- gold Open Access which fosters wider collaboration and increased citations

- maximum visibility for your research: over $100 \mathrm{M}$ website views per year

At BMC, research is always in progress.

Learn more biomedcentral.com/submissions 